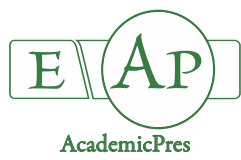

\title{
Growth, Photosynthetic Pigments, Phenolic, Glucosinolates Content and Antioxidant Capacity of Broccoli Sprouts in Response to Nanoselenium Particles Supply
}

\author{
Simona I. VICAS ${ }^{1}$, Simona CAVALU², Vasile LASLO $^{1}$, Mariana TOCAI ${ }^{3}$, \\ Traian O. COSTEA ${ }^{4}$, Liviu MOLDOVAN ${ }^{5}$ \\ ${ }^{1}$ University of Oradea, Faculty of Environmental Protection, 26 Gen. Magheru St., 410048, Oradea, \\ Romania;sim_vicas@yahoo.com; vasilelaslo@yahoo.com \\ ${ }^{2}$ University of Oradea, Faculty of Medicine and Pharmacy, 10 P-ta 1 Decembrie, 410087, Oradea, \\ Romania; simona.cavalu@gmail.com (*orresponding author) \\ ${ }^{3}$ University of Oradea, Biomedical Sciences Doctoral School, 1 University St., 410087, Oradea, Romania; tc_mariana@yahoo.com \\ ${ }^{4}$ University of Oradea, Industrial Engineering Doctoral School, 1 University St., 410087, Oradea, Romania; costea.traian.octavian@gmail.com \\ ${ }^{5}$ University of Oradea, Faculty of Electrical Engineering and Information Technology, 1 University St., 410087, Oradea, \\ Romania; liviu@uoradea.ro
}

\begin{abstract}
Improving the nutritional quality of plants has emerged from the fact that macro- and micro- nutrients are limited in various agricultural areas. The aim of our study was the biofortification of broccoli sprouts with selenium nanoparticles (NSePs) and evaluation of growth parameters, assimilator pigments content, total phenols, glucosinolates content along with antioxidant capacity, in order to boost value added output, such as improved nutrition and food functionality. NSePs were prepared by reduction of $\mathrm{NaHSeO}_{3}$ using glucose as reducing agent, and characterized from structural and morphological point of view. The growth of broccoli seedlings was dependent on NSePs concentration. The treatment with 10 and $50 \mathrm{ppm}$ NSePs caused a slight increase in total biomass, by contrast with $100 \mathrm{ppm}$ treatment. Chlorophyll content, total carotenoid and total phenols content was not affected by the treatment of broccoli sprouts with different concentrations of NSePs. Instead, the content of individual glucosinolates varied between the samples, depending on the levels of NSePs. The highest antioxidant capacity was obtained for $100 \mathrm{ppm}$ NSePs concentration. The effective uptake of NSePs was further demonstrated by FTIR spectroscopy and Hyperspectral Microscopy. NSePs did not induce any toxicity on broccoli sprouts. Moreover, broccoli supply with NSePs may target higher nutritional impact and health benefits.
\end{abstract}

Keywords: Brassica oleracea; DPPH; FRAP; FTIR; glucosinolates; HPLC; hyperspectral microscopy; selenium

\section{Introduction}

The research focused towards improving the nutritional quality of plants has emerged from the fact that macro- and micro- nutrients are limited in various agricultural areas, depending on the soil topography, climate and agricultural or industrial utilization (Stolfa et al., 2017).

Selenium is essential for life and has attracted growing interest in both human health and agricultural field of science (Reilly, 2006) due to its ability to annihilate toxic effects induce by heavy metals or ionizing radiation exposure (Bassem et al., 2012; Hassanin et al., 2013). One of the possibilities to increase the selenium intake is by the diet of people, or used them as agricultural fertilizers (Ducsay et al., 2006; Jiang et al., 2015). Selenium uptake by plants, from the soil, is strongly related to the form in which this element occurs in the soil: elemental selenium, selenite, selenate, in association with other elements or in organic forms (Khoei et al., 2017).

There are many publications that investigated the bioavailability of different inorganic forms of Selenium (Sajedi et al., 2011; Barickman et al., 2014; Trolove et al., 2018; Islam et al., 2018) for plants but for the first time, the bioavailability of Selenium in the form of nanoparticles in the broccoli sprouts and its effect on the bioactive compounds was investigated. 
822

In food products (both vegetable and meat), selenium occurs in combination with proteins, being demonstrated that in terms of dairy products, selenium levels are negatively correlated with fat content (Reilly, 2006). It seems that plants that are rich in sulphur (such as members of Liliaceae family-onions and garlic, Cruciferae familiycabbage and broccoli) are expected to reach high level of accumulated selenium (Abdulah et al., 2009). Years ago, it was generally considered about elemental selenium to be biologically inert, but recently, some researchers proved that nanoSelenium (NSe) has similar bioavailability to other selenium forms (Zhang et al., 2008) and reported that NSe not only has a higher efficiency in up-regulating selenoenzymes, but also seems to be less toxic comparing with selenite. These results indicated that NSe can serve as an antioxidant with reduced risk of toxicity, showing a better absorption into plants, animals, humans and microorganisms (Cavalu et al., 2017). However, the uptake of Selenium by plants depends on several factors: plant capacity to accumulate, soil composition and environmental factors (El-Ramady et al., 2015). The agronomic biofortification with Selenium supplemented fertilizers to target the greatest nutritional impact and health benefits is a result of rapid emerging biotechnologies.

Glucosinolates (GLS) ( $\beta$-thioglucoside-N-hydroxysulphates) are very important plant secondary metabolites, specific to Brassica crops, like broccoli (Brassica oleracea var. italica) (Vicas et al., 2013). The most abundant GLS in broccoli are glucobrassicin, neoglucobrassicin, glucoraphanin, glucoiberin (Tian et al., 2005; Barbieri et al., 2008). The GLS have demonstrated chemoprotective effects against different types of cancer, and their level has been found to be greater in sprouts than in mature plants (Tarasevičienè $e t$ al., 2009).

The aim of our study was the supply with NSePs of broccoli sprouts, the evaluation of growth parameters, the content of photosynthetic pigments, total phenols, glucosinolates and antioxidant capacity, in order to enhance value added output, such as improved nutrition and food functionality. To our knowledge, there are no references in literature regarding the influence of $\mathrm{NSePs}$ addition during germination of Brassica seeds; only few works were reported, in which inorganic Selenium forms were added to the seeds during germination period (Ávila et al., 2014; Piekarska et al., 2014; Bachiega et al., 2016).

\section{Materials and Methods}

Preparation and morphological characterization of selenium nanoparticles

NSePs were prepared by chemical reduction of $\mathrm{NaHSeO}_{3}$ solution with freshly prepared $0.25 \%$ glucose solution (Cavalu et al., 2018). The ratio between selenium salt and glucose was $4: 1(\mathrm{~mol} / \mathrm{mol})$. The mixture was heated to $120{ }^{\circ} \mathrm{C}$ for $15 \mathrm{~min}$ (until the characteristic red colour of nano-Se was achived) and, after cooling, was centrifuged at $6000 \mathrm{rpm}$ for $10 \mathrm{~min}$. The supernatant was removed, and the red NSePs were washed with distilled water, followed by repeated centrifugation (4 times). Finally, distillated water was added to obtain a colloidal solution and stored at room temperature. Dynamic Light Scattering (DLS) was applied to colloidal solution, using ZEN 3690 (Malvern Instruments), in order to determine the average particle size and size distribution. AFM microscopy (SPM/AFM 5500 Keysight Technologies) was applied in order to observe the morphology and surface topography of the drop-coated film of NSePs.

\section{Plant material and experimental design}

The research was performed using broccoli seeds $(B$. oleracea L. botrytis subvar. Cymosa, Agrosel Company, Romania). Seeds were germinated in plastic box $(25 \times 20$ $\mathrm{cm}$ ), on filter paper, 250 seeds per box, sprinkled every day with different concentration of NSePs $(10,50$ and 100 $\mathrm{ppm}$ ) and distilled water as a control. The germination was carried out on a plant growth chamber with controlled temperature $\left(25^{\circ} \mathrm{C}\right)$ and photoperiod $(16 \mathrm{~h}$ of light, $8 \mathrm{~h}$ in the dark) during 9 days. After germination, broccoli sprouts were harvested, freeze-dried and stored at $-20^{\circ} \mathrm{C}$ until the investigation.

Percentage of germination was determined after $48 \mathrm{~h}$ from the start of the experiment. Samples from three replicates were harvested after 9 days. The roots, shoots and leaves were separated and weighted immediately after harvesting. Values were expressed in grams per 20 sprouts. The biomass of fresh broccoli sprouts was calculated by weighing the entire broccoli sprouts (root, shoot and leaves) and expressed as grams per 20 broccoli sprouts. In order to extract photosynthetic pigments, $50 \mathrm{mg}$ of fresh broccoli sprouts leaves were homogenized with $5 \mathrm{ml}$ DMF (N,Ndimethylformamide) following the protocol described by Sharma et al. 2011.

\section{Extraction and HPLC analysis of GLS from broccoli} sprouts

The extraction method of GLS from broccoli sprouts was made according to the EEC Regulation N1864/90. Shortly, duplicated samples (200 mg powder) were place in a hot water bath $\left(80^{\circ} \mathrm{C}\right)$, left for $5 \mathrm{~min}$ and then extracted with $5 \mathrm{ml}$ hot ethanol $70 \%$ for 3 min using Silent Crusher M (Heidolph) homogenizer, at $5000 \mathrm{rpm}$. Then, the mixtures were centrifuged at $5000 \mathrm{rpm}$ for $20 \mathrm{~min}$. Aliquots of $1 \mathrm{ml}$ supernatant were loaded twice on a mini-column filled with $0.6 \mathrm{ml}$ DEAE-Sephadex A- 25 anion-exchange resin, conditioned with $25 \mathrm{mM}$ acetate buffer $\mathrm{pH}$ 5.6. After washing with $3 \mathrm{ml}$ acetate buffer, volume of $200 \mu \mathrm{l}$ purified sulphatase were loaded on each mini-column, left overnight at room temperature and the desulfo-GLS were eluted with $3 \mathrm{ml}$ of ultra-pure water, then filtered through a $0.45 \mathrm{ml}$ filter and analyzed by HPLC. A known amount of glucotropaeolin (200 $\mu \mathrm{l}$ from a solution containing $1 \mathrm{mg} / \mathrm{ml}$ ) was added to each broccoli sprouts samples before the first extraction, as an internal standard for the HPLC analysis.

The quantification of GLS from broccoli sprouts extracts was performed by an HPLC-PDA system (Shimadzu Corporation, Scientific Instruments, Kyoto, Japan) equipped with a CBM-20A controller, LC-20 AD pump, a DGU-20A degaser, a SIL-20 AC autosampler, CTO-20 AC column oven and a SPD-M20A photodiode array detector. Desulfo-GLS were separated on a Platinum 
(C 18) 100 A column $(250 \times 4.6 \mathrm{~mm}, 5 \mu \mathrm{m})$, at $30^{\circ} \mathrm{C}$, using a flow rate of $0.5 \mathrm{ml} / \mathrm{min}$ and an injection volume of $20 \mu \mathrm{l}$. The data were processed using Labsolution version 5.10.153 (Shimadzu) software. The mobile phases consisted of water (eluent A) and acetonitrile (eluent B), using a gradient program as follows: 1 min $1 \% \mathrm{~B} ; 22$ min linear gradient up to $22 \% \mathrm{~B} ; 10 \mathrm{~min}$ linear gradient down to $1 \% \mathrm{~B}$. Elution of desulfo-GLS was monitored at $229 \mathrm{~nm}$. The desulfo-GLS was identified by retention time using the standards and UV-Vis spectra. The content of individual and total GLS, expressed in $\mu \mathrm{mol} / \mathrm{g}$ dry weight $(\mathrm{dw})$ was calculated using glucotropaeolin as an internal standard, considering the response factors of the other desulfo-GLS relative to the desulfo-glucotropaeolin.

The total phenols content and antioxidant capacity of broccoli sprouts

In order to determine the total phenols content and antioxidant capacity, the powder of each sample $(20 \mathrm{mg})$ was suspended in methanol $(1 \mathrm{ml})$, sonicated for 10 minutes, centrifuged at $5000 \mathrm{rpm}$ for $15 \mathrm{~min}$ and the supernatant was used for the analysis. The total phenols content was determined by using modified Folin-Ciocalteu method (Singleton et al., 1999). Briefly, aliquots of $100 \mu \mathrm{l}$ Brassica sprouts extracts were mixed with $1700 \mu$ distilled water, $200 \mu \mathrm{l}$ Folin-Ciocalteu reagent (diluted 1:10, v/v) and $1000 \mu \mathrm{l}$ of $7.5 \% \mathrm{Na}_{2} \mathrm{CO}_{3}$ solution. The mixture was incubated in the dark, at room temperature for $2 \mathrm{~h}$. The absorbance was measured at $765 \mathrm{~nm}$, and the results were expressed in $\mathrm{mg}$ gallic acid equivalents (GAE)/g dw.

Evaluation of the ferric reducing antioxidant power (FRAP) of broccoli sprouts extracts was performed by Benzie and Strain method (1996). The absorption of the coloured complex (ferrous tripyridyltriazine) resulted by the reaction between Brassica sprouts extract and FRAP reagent was recorded at $595 \mathrm{~nm}$ and the results were expressed in $\mu \mathrm{mol} \mathrm{TE} / \mathrm{g} \mathrm{dw}$.

The free radical scavenging capacity of broccoli sprouts extracts against the stable radical DPPH (2,2-diphenyl-1picrylhydrazyl) was performed using Brand-Williams method (Brand-Wiliams et al., 1995). Briefly, a volume of $200 \mu \mathrm{l}$ of broccoli extract and $2.8 \mathrm{ml} \mathrm{DPPH}$ solution $(80$ $\mu \mathrm{M})$ were mixed and the decreased in the absorbance was monitored at $515 \mathrm{~nm}$ for 5 minutes. The percentage of scavenging effect of extract against $\mathrm{DPPH}$ radicals, was calculated using the following equation:

DPPH scavenging effect $(\%)=[(\mathrm{A} 0$-As $) \times 100] / \mathrm{A} 0$, where, A0 is absorbance of the blank, and As is absorbance of the sample at $515 \mathrm{~nm}$.

FTIR (Fourier Transform Infrared Spectroscopy) of broccoli sprouts enriched in nano-Se

FTIR spectra of broccoli sprouts leaves were recorded in the range $400-4000 \mathrm{~cm}^{-1}$, using Spectrum BXII spectrophotometer (Perkin Elmer), equipped with MIRacle ATR accessory (ZnSe crystal), at scanning speed of $32 \mathrm{~cm}^{-1}$ and spectral width $2.0 \mathrm{~cm}^{-1}$. A comparison was made between the spectra recorded for different concentrations of nano-Se used in the germination period, and the reference spectrum (no selenium added).
Mapping nano-Se particles in broccoli sprouts by Enhanced Darkfield Hyperspectral Microscopy and CytoViva unit

Broccoli leaves were mounted directly on a glass slide with a coverslip. The CytoViva - microscope system was adapted to acquire dark field microscopy images and hyperspectral plots using an enhanced dark field transmission optical microscope (Olympus BX41) equipped with a CytoViva unit and a hyperspectral imaging spectrophotometer unit (Headwall Photonics). The captured optical images were computed and analysed with special software (ImageJ Software). Qualitative hyperspectral analysis of the acquired images was performed using ENVI 4.8 Spectral libraries.

\section{Statistical analysis}

Based on experimental design, four samples groups were established: control (no selenium supply), $\mathrm{Br} \_10, \mathrm{Br} \_50$, $\mathrm{Br} 100$ and analysed in triplicate. Statistical significance between the groups was determined by one-way ANOVA, Tukey's Multiple Comparison Test. A value of $\mathrm{p}<0.05$ was considered statistically significant.

\section{Results and Discussion}

\section{Preparation and morphological characterization of selenium nanoparticles}

Particle size and size distribution of NSe was determined by DLS measurement, as presented in Fig. 1a. The histograms demonstrates the co-existence two different specimens: the first one with average size of $100 \mathrm{~nm}$ and lower concentration, and second one, with average size of about $650 \mathrm{~nm}$ and higher concentration. The larger specimens occur because of nanoparticles aggregation. It was previously demonstrated (Zhang et al., 2012) that even at room temperature, NSePs tends to aggregate into larger size spheres, due to their high surface to volume ratio. AFM images of single selenium particles, spherical shape, indicates a diameter ranging from $200 \mathrm{~nm}$ to $700 \mathrm{~nm}$, the maximum high being $220 \mathrm{~nm}$, as presented in Fig. 1b. The majority of the particles was symmetrical, spherical in shape and well distributed without aggregation. The size of NSePs is considered to be in agreement with the data collected from the DLS study. However, NSePs appear larger on AFM micrographs, as they are flattened due to the contact with the substrate.

\section{Effect of nano-Se supply on growth parameters}

Under the treatment with three different concentrations of NSePs (10, 50 and $100 \mathrm{ppm}$ ), the germination of broccoli seeds was not affected by the presence of NSePs (data not shown). On the other hand, the growth of seedlings was dependent on Se concentration, as presented in Fig. 2. Compared to the control, the treatment with 10 and $50 \mathrm{ppm} \mathrm{NSePs}$ caused a slight increase in total biomass, while the treatment with $100 \mathrm{ppm}$ caused a slight decrease, statistically significant compared with the $\mathrm{Br}$-50 group (Fig. 2a). In the same time, compared to the control, $10 \mathrm{ppm}$ and $50 \mathrm{ppm}$ NSePs supply induced an increased weight of broccoli roots, while $100 \mathrm{ppm}$ 

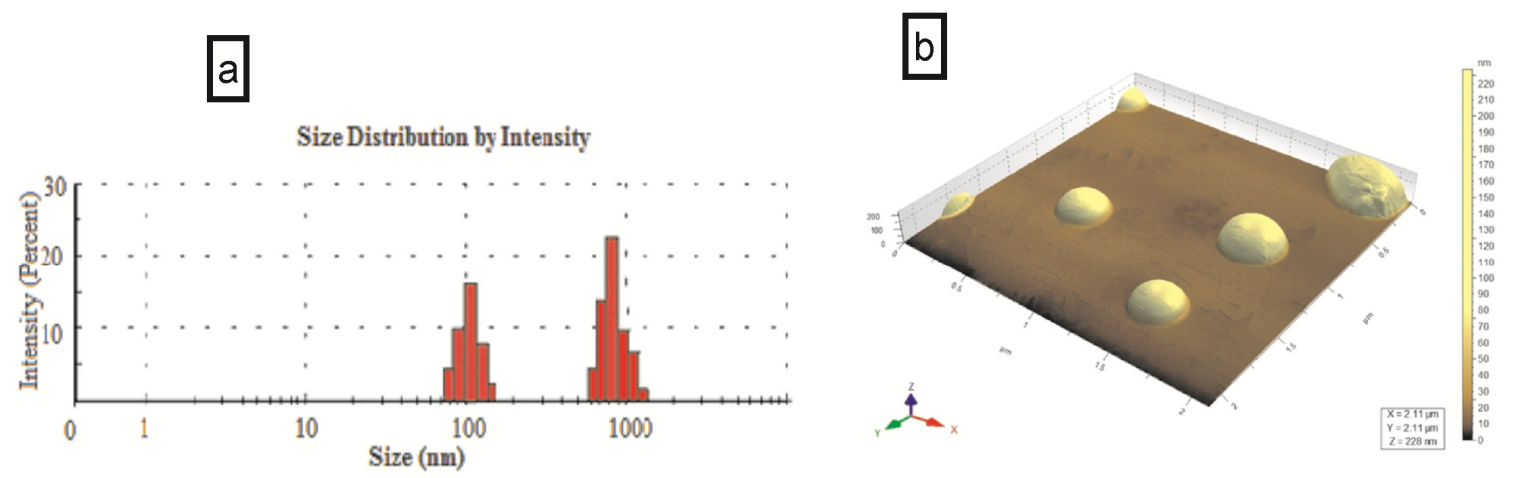

- Record 01: SeNP 1001

Fig. 1. a) Size distribution of NSePs b) 3D micrograph of Selenium nano-spheres
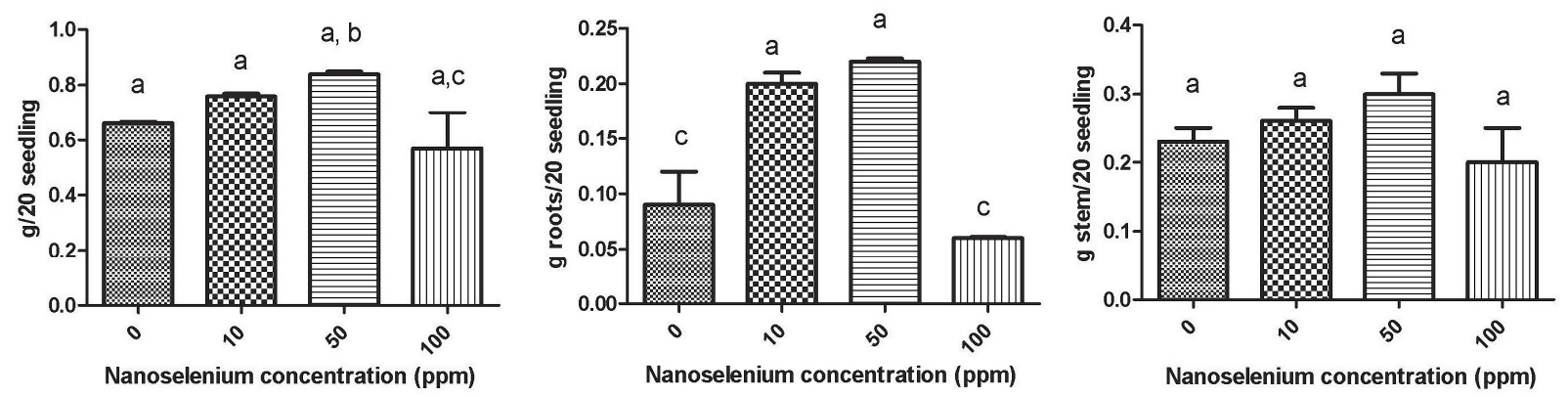

Fig. 2. Effect of NSePs particles supply on: a) Total biomass; b) Root weight; c) Shoot weight. Values are the means of three replications. Error bars represent standard deviation. Different lower case letters reflect the significantly different $(p<0.05)$ between the control and samples

induced a drastic decrease compared to the $\mathrm{Br} \_10$ and Br_50 groups, but not statistically significant compared to the control (Fig. 2b). We have noticed that NSePs supply had no effect on the weight of shoots (Fig. 2c). These results are in agreement with Ramos et al. (2010), which demonstrated that sodium selenite supply exhibited an increased shoot/root weight and biomass production.

\section{Effect of nano-Se supply on photosynthetic pigments production}

Fig. 3 exhibits the effect of different NSePs concentrations on clorophylls and total carotenoids content. A significantly increase in amount of chlorophyll a was recorded in the case of broccoli sprouts treated with 100 ppm, compared to the control. The content of clorophyll $\underline{b}$ and total carotenoids was not affected by the treatment with $\mathrm{NSePs}$, as compared to the control group. The ratio chlorophyll $\underline{a} /$ chlorophyll $\underline{b}$ is a valuable indicator which provides information about the activity of the lightharvesting complex (LHC) from Photosystem II (Taran et al., 2016). The inset in Fig. 3 presents the ratio chlorophyll $\underline{a}$ /chlorophyll b, indicating that no matter the concentration of NSePs, the ratio remains almost constant.

Effect of NSePs supply on total phenols content and antioxidant capacity

The major group of biologically active compounds that may contribute to the total antioxidant capacity includes different groups of polyphenols (flavonoids, hydroxyl- cinnamic acids). The treatment of broccoli sprouts with different concentrations of NSePs did not affected the content of total phenols, as shown in Fig. 4a. Some previous phytotoxicity studies showed that nanoparticles could induce stress in plants by manipulating the endogenous mechanisms (El-Ramady et al., 2015). In response to these stress, plants releases various defensive compounds known as antioxidant secondary metabolites. In our study, the amount of total phenols did not show any modification comparing to the control, which suggests that NSePs treatment has no consequence in broccoli sprout stress. In Fig. $4 b$ and $c$ is presented the effect of NSePs treatment on antioxidant capacity of broccoli sprouts, determined by DPPH assay and FRAP assay, respectively.

Compared to the control, the antioxidant capacity of broccoli sprouts (determined by DPPH assay) from $\mathrm{Br} \_10$ and $\mathrm{Br} \_50$ groups were not significantly affected. In contrast, the group $\mathrm{Br} \_100$ exhibited the highest antioxidant capacity compared both to the control and other two groups. It is well known that phenols content and antioxidant capacity are directly correlated (Rychlik et al., 2015). In our case, even if $\mathrm{Br} 100$ group did not exhibit enhaced amount of total phenols, the antioxidant capacity showed the highest level. An explanation might be related to the fact that NSePs itself acts as a scavenger with respect to DPPH free radical, as demonstrated by Huang et al. (2003). The antioxidant efficacy was evaluated also by FRAP assay. Our results shown that the ability of broccoli extracts to reduce $\mathrm{Fe}^{3+}$ to $\mathrm{Fe}^{2+}$ was not influenced on the 


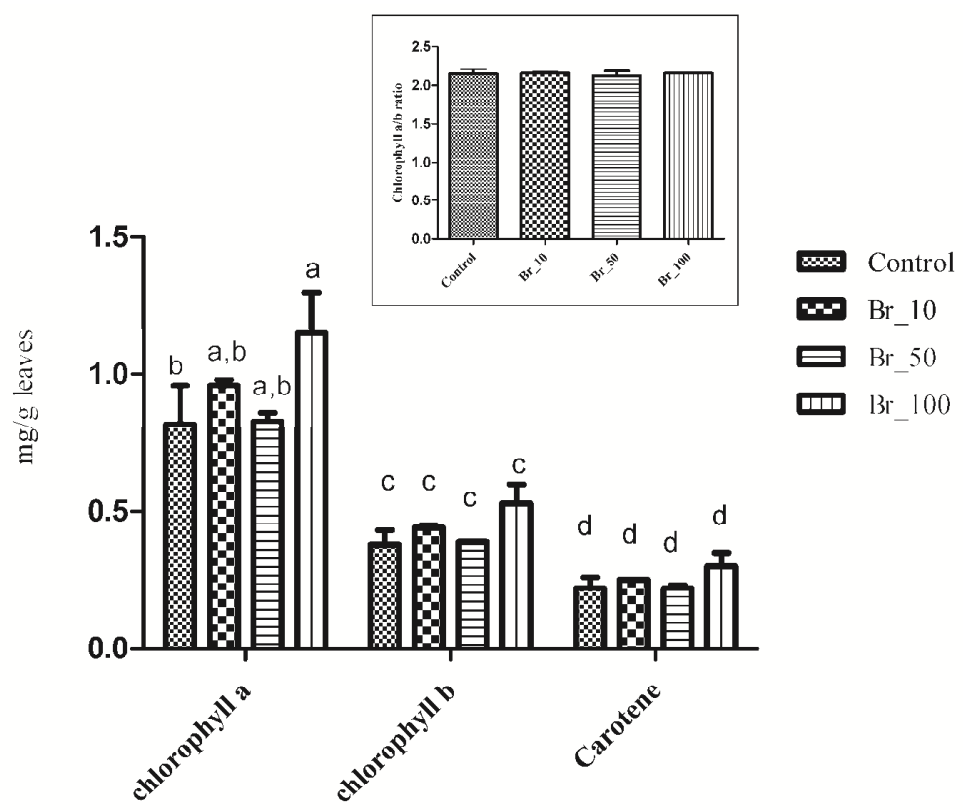

Fig. 3. Effect of NSePs treatment on green pigments content and total carotenoids. Inset, chlorophyll a/chlorophyll b ratio. Values are the means of three replications. Error bars represent standard deviation. Different lower case letters reflect the significantly different $(\mathrm{p}<0.05)$ between the control and samples
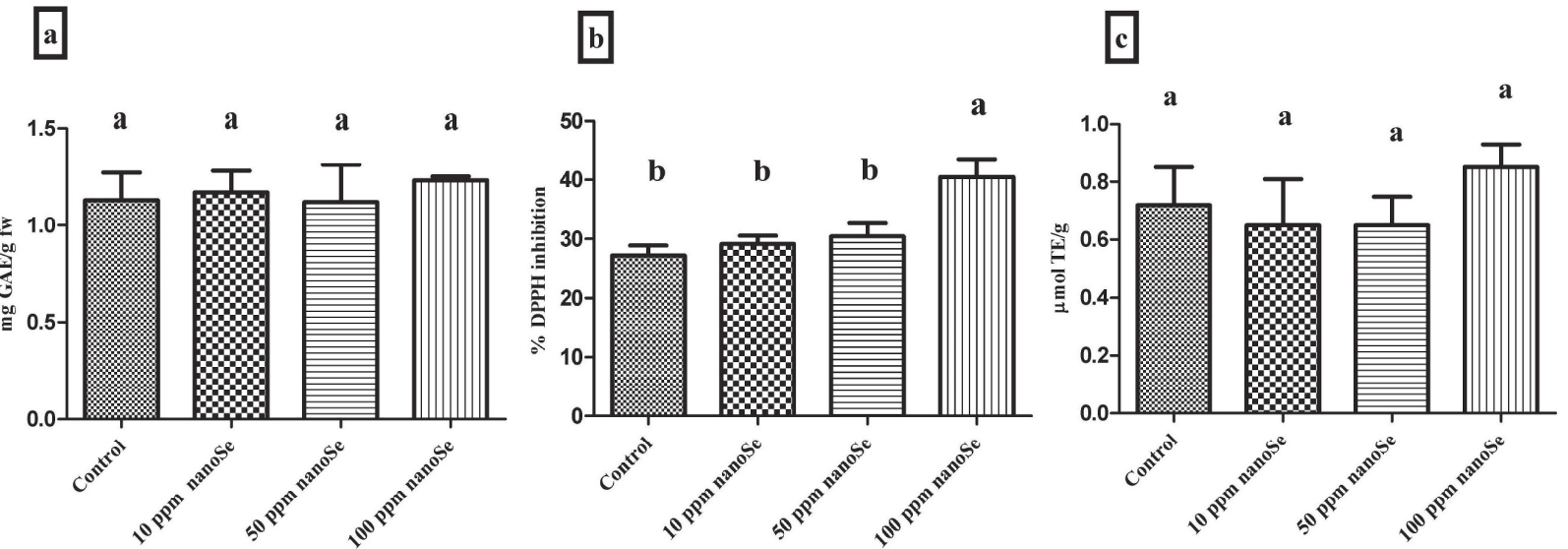

Fig. 4. Effect of NSePs treatments on: a) total phenols content; b) antioxidant capacity determined by DPPH assay; c) antioxidant capacity determined by FRAP assay. Values are the means of three replications. Error bars represent standard deviation. Different lower case letters reflect the significantly different $(\mathrm{p}<0.05)$ between the control and samples

concentration of NSePs. This finding supports our above mentioned results, indicating that neither the concentration, or the size of NSePs used in our experiment, doesn't induced any toxicity on broccoli sprouts.

The Effect of NSePs on individual GLS in broccoli sprouts HPLC-PDA was applied in order to determine the content of individual GLS from broccoli sprouts of 9 days old germination (HPLC chromatogram is shown in Fig. 5).

Eight different GLS were detected in broccoli sprouts (9 days old) enriched with $\mathrm{NSePs}$ with different concentrations (Table 1). It can be noticed that the content of individual GLS varied between the samples.
The precursor of the anticarcinogenic sulforaphane, GRA, was present in all samples, and the highest concentration was obtained in the case of broccoli sprouts supply with 100 ppm NSePs. Other aliphatic GLS, glucoerucin (GER) was found to have a decreased value in the samples with NSePs compared with the control. Instead, the indolic GLS class showed no statistical significance between the samples.

Barickman et al. (2014) investigated the impact of sodium selenate on glucosinolates concentrations in rapid cycling Brassica oleracea. Their results demonstrated that in B. oleraceae the increasing of selenium concentrations did not have significant decreases in glucosinolates (Fig. 5). 
Table 1.Content of different GLS $(\mu \mathrm{mol} / \mathrm{g} \mathrm{dw})$ separated from broccoli sprouts grown under different concentrations of NSePs

\begin{tabular}{|c|c|c|c|c|c|c|c|c|c|c|}
\hline \multirow{2}{*}{$\begin{array}{c}\text { Peak } \\
\text { Number }\end{array}$} & \multirow{2}{*}{ GLS } & \multirow{2}{*}{ RT } & Control & \multirow{2}{*}{ sd } & $10 \mathrm{NSeP}$ & \multirow{2}{*}{ sd } & $50 \mathrm{NSeP}$ & \multirow{2}{*}{$\mathrm{sd}$} & $100 \mathrm{NSeP}$ & \multirow{2}{*}{ sd } \\
\hline & & & mean & & mean & & mean & & mean & \\
\hline 1 & $\begin{array}{l}\text { PRO } \\
\end{array}$ & 5.6 & 2.58 & 0.21 & $0.58^{* * *}$ & 0.08 & 2.10 & 0.76 & 2.42 & 0.09 \\
\hline 2 & GIB & 7.9 & 1.93 & 0.34 & $0.45^{* *}$ & 0.09 & 1.97 & 0.22 & 2.93 & 0.76 \\
\hline 3 & GRA & 10.2 & 4.78 & 1.77 & $1.12^{* * *}$ & 0.61 & 5.59 & 0.81 & $6.90^{* * *}$ & 0.87 \\
\hline 4 & 4OHGBS & 16.4 & 0.19 & 0.19 & 0.058 & 0.04 & 0.36 & 0.17 & 0.29 & 0.05 \\
\hline 5 & GER & 19.5 & 4.97 & 0.40 & $1.02^{* * *}$ & 0.35 & $3.00^{* *}$ & 0.71 & $3.43^{* *}$ & 0.42 \\
\hline 6 & GBS & 21.3 & 0.25 & 0.1 & 0.08 & 0.01 & 0.22 & 0.06 & 0.31 & 0.05 \\
\hline 7 & MeGBS & 24.8 & 0.32 & 0.01 & 0.18 & 0.03 & 0.35 & 0.02 & 0.35 & 0.07 \\
\hline 8 & NGBS & 28.4 & 0.45 & 0.11 & 0.25 & 0.04 & 0.34 & 0.16 & 0.31 & 0.05 \\
\hline
\end{tabular}

Legend: PRO- Progoitrin, GIB- Glucoiberin, GRA- Glucoraphanin, 4OHGBS- 4-hydroxyglucobrassicin, GER- glucoerucin, GBS- Glucobrassicin, MeGBSmethoxyglucobrassicin, NGBS- Neoglucobrassicin, RT- retention time. Values are the means of three replications. sd- standard deviation. Statistical significance: ${ }^{* *} \mathrm{p}<$ 0.01 and ${ }^{* * *} \mathrm{p}<0.001$.

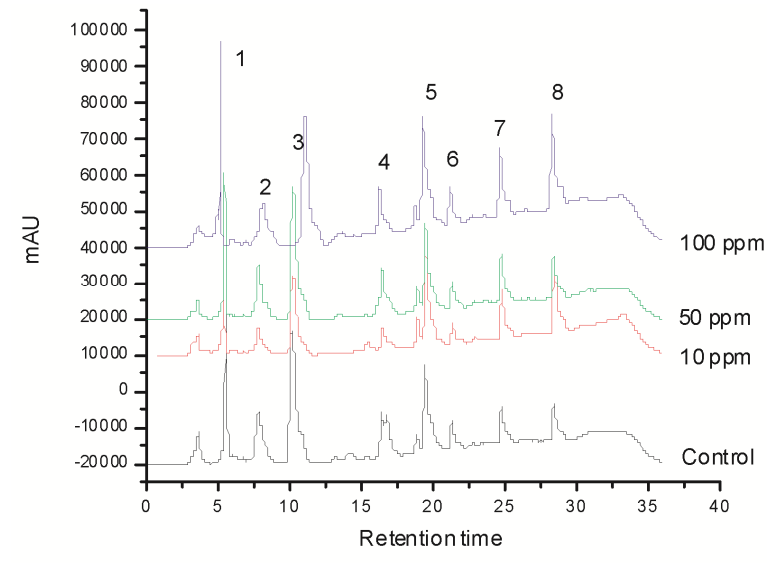

Fig. 5. HPLC profile of individual glucosinolates in broccoli sprouts ( 9 days old) grown under different concentrations of NSePs (10, 50 and $100 \mathrm{ppm})$. 1. PRO- Progoitrin, 2. GIBGlucoiberin, 3. GRA- Glucoraphanin, 4. 4OHGBS- 4hydroxyglucobrassicin, 5. GER- glucoerucin, 6. GBSGlucobrassicin,7. MeGBS- methoxyglucobrassicin, 8. NGBSNeoglucobrassicin leaves

FTIR spectroscopy characterization of broccoli sprouts

The FTIR spectra were recorded for each broccoli sprout specimen, corresponding to different NSePs concentrations, along with the reference spectrum (no selenium added), as displayed in Fig. 6. The overall features in this figure are dominated by the vibrational fingerprints of chlorophyll (Da Luz, 2006). The band at $1643 \mathrm{~cm}^{-1}$ in the reference spectrum is assigned to carbonyl stretching vibration ( $\mathrm{C}=\mathrm{O}$ bonds originating from ester groups), the strong band at $1046 \mathrm{~cm}-1$ to carboxyl stretching mode (C$\mathrm{O}-\mathrm{C}$ ), while the doublet at 2850 and $2926 \mathrm{~cm}^{-1}$ is assigned to methylene stretching. Comparing to the reference spectrum (no NSePs added), important structural changes are observed: the intensity of the marker bands appears to be dependent on the concentration of selenium and shifted toward higher wavenumbers, concomitant with the modification of the relative intensity. This behavior indicates that NSePs are effectively taken up by the plant and then metabolized.

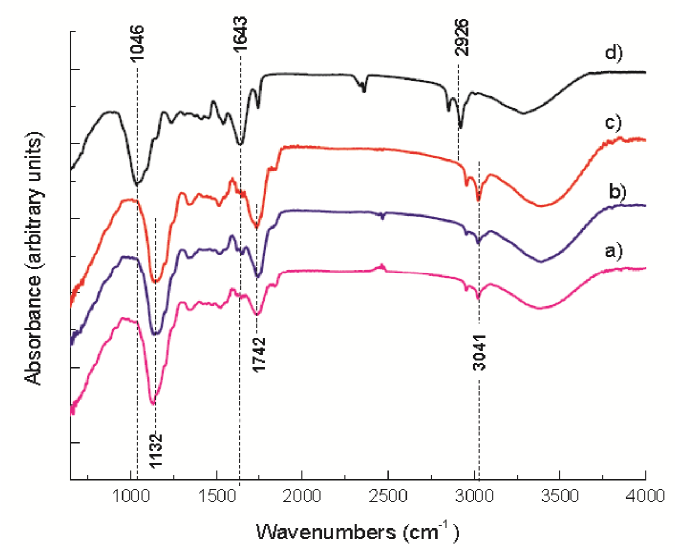

Fig. 6. FTIR spectra of broccoli sprouts leaves upon NSePs treatment: a) $100 \mathrm{ppm}$; b) $50 \mathrm{ppm}$; c) $10 \mathrm{ppm}$; d) reference spectrum

\section{Mapping nano-Se particles in situ}

Using integrated hyperspectral image analysis software, the unique spectral response of nanoparticles were identified and easily mapped throughout the plant tissue. In Fig. 7a, the hyperspectral image of a leaf containing NSePs is shown as the dark reddish-brown area encircled. In Fig. 7c we have captured the spectral response for both the leaf (indicated in green) and NSePs (indicated in red). The spectral response of NSePs does share much of the spectral characteristics of the leaf due to the chlorophyll influence. However, the presence of selenium causes a shift of the spectral peak from $565 \mathrm{~nm}$ (in the leaf tissue) to $610 \mathrm{~nm}$. Finally, the spectral library was mapped against the positive control image, and, as can be seen in the encircled area of Fig. $7 \mathrm{~b}$, all pixels perfectly matching the spectral response of the selenium were pseudo-colored red. Therefore, by using this high sensitivity technique, we were able to demonstrate NSePs uptaking by broccoli sprouts.

The results are in good agreement with previously reported data (El-Ramady et al., 2015), supporting the idea that selenium from soil is up taken by plants in the form of selenate $\left(\mathrm{Se}^{6+}\right)$, and then metabolized via the sulphur assimilation pathway, where selenate is reduced to selenite $\left(\mathrm{Se}^{4+}\right)$, which can undergo further reduction to selenide $\left(\mathrm{Se}^{2-}\right)$. 

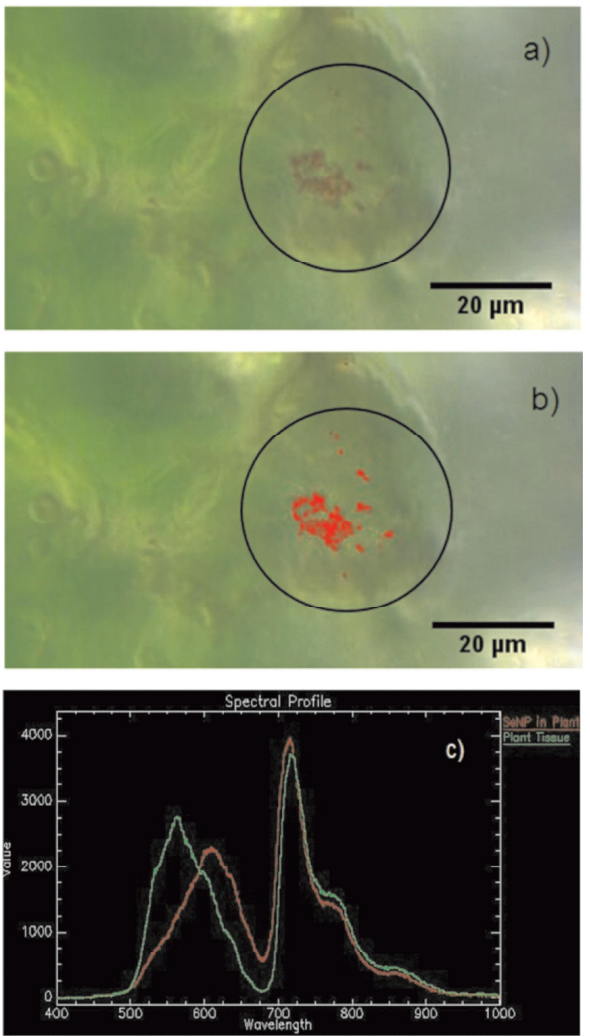

Fig. 7. Enhanced Darkfield Hyperspectral images of Se uptaken: a) 60x image of Se in broccoli leaf; b) 60x image of the leaf with Se mapped and pseudo-colored in red; c) Spectral comparison of plant tissue and Se in broccoli leaf (green lineplant tissue; red line-selenium)

\section{Conclusions}

The main goal of our study was to modify the nutritional content of broccoli sprouts, by NSePs supplementation, during germination process. Growth parameters, assimilator pigments content, total phenols content and antioxidant capacity of broccoli sprouts were evaluated. The growth of seedlings was depent on NSe concentration. The treatment with 10 and 50 ppm NSe caused a slight increase in total biomass, by contrast with $100 \mathrm{ppm}$ treatment. A significantly increase in amount of chlorophyll a was recorded in the case of broccoli sprouts leaves treated with $100 \mathrm{ppm}$. The content in clorophyll $\underline{b}$ and total carotene was not affected by the treatment with nanoSe particles. The concentration of 100 ppm NSe particles was reflected in the highest antioxidant capacity. Our results demonstrated that NSe particles in concentration of 10,50 and 100 ppm didn't induce any toxicity on broccoli sprouts. The effective uptake of NSe was further demonstrated by ATR-FTIR spectroscopy and Enhanced Darkfield Hyperspectral Microscopy coupled with CytoViva unit. However, the complete understanding of NSe metabolism in vegetables sources requires more detailed biochemical studies and selenium uptake analysis to be conducted, especially from quantitative point of view.

\section{Acknowledgements}

This work was supported by a grant of the Romanian National Authority for Scientific Research and Innovation CNCS/CCCDI-UEFISCDI, project number PN-III-P22.1-PED-2016-1846 within PNCDI III. The author L. Moldovan acknowledge the support in acquiring AFM device from "Hungarian - Romanian Research Platform for Smart Materials Research”, HURO/1101/191/2.2.1, HuRo Cross-border Cooperation Programme 2007-2013. The support of Dr. Byron Cheatham for recording the images with Enhanced Darkfield Hyperspectral Microscopy CytoViva is highly acknowledged.

\section{Conflicts of interest}

The authors declare that there are no conflicts of interest related to this article.

\section{References}

Abdulah R, Faried A, Kobayashi K, Yamazaki C, Suradji EW, Ito K, ... Koyama H (2009). Selenium enrichment of broccoli sprout extract increases chemo sensitivity and apoptosis of $\mathrm{LNCaP}$ prostate cancer cells. BMCCancer 9(1):414.

Ávila FW, Yang Y, Faquin V, Ramos SJ, Guilherme LRG, Theodore W, ... Li L (2014). Impact of selenium supply on Se-methylselenocysteine and glucosinolate accumulation in selenium-biofortified Brassica sprouts. Food Chemistry 165:578-586.

Bachiega P, Salgado JM, Ernesto de Carvalho J, Ruiz ALTG, Schwarz K, Tezotto T, Morzelle MC (2016). Antioxidant and antiproliferative activities in different maturation stages of broccoli (Brassica oleracea Italica) biofortified with selenium. Food Chemistry 190:771-776.

Barbieri G, Pernice R, Maggio A, De Pascale S, Fogliano V (2008). Glucosinolates profile of Brassica rapa L. subsp. sylvestris L. Janch. var. esculenta. Hort. Food Chemistry 107(4):1687-1691.

Barickman TC, Kopsell DA, Sams CE (2014). Impact of selenium fertilization on glucosinolate concentration in Arabidopsis thaliana and rapid cycling Brassica oleracea. Journal of Plant Nutrition 37(3):343-356.

Bassem MR, Samir WA, Mahmoud HK (2012). Met-hemoglobin concentration reduction and methemoglobin reductase enhancement after applying of $\alpha$-Tocopherol and selenium combination as a radio protector against ionizing radiation exposure. Wulfenia Journal 19(10):373-389.

Benzie IF, Strain JJ (1996). The ferric reducing ability of plasma (FRAP) as a measure of "antioxidant power": the FRAP assay. Analytical Biochemistry 239(1):70-76.

Brand-Williams W, Cuvelier ME, Berset C (1995). Use of free radical method to evaluate antioxidant activity. LWT-Food Science and Technology 28(1):25-30.

Cavalu S, Prokisch J, Laslo V, Vicas S (2017). Preparation, Structural Characterisation and Release Study of Novel Hybrid Microspheres Entrapping Nano-Selenium, Produced by Green Synthesis. IET Nanobiotechnology 11 (4):426-432. 
828

Cavalu S, Antoniac IV, Fritea L, Mates IM, Milea C, Laslo V, Vicas S, Mohan A (2018). Surface modifications of the titanium mesh for cranioplasty using selenium nanoparticles coating. Journal of Adhesion Science and Technology 32 (22):2509-2522.

Da Luz BR (2006). Attenuated total reflectance spectroscopy of plant leaves: a tool for ecological and botanical studies. New Phytologist 172(2):305318.

Ducsay L, Ložek O (2006). Effect of selenium foliar application on its content in winter wheat grain. Plant, Soil and Environment 52(2):7882.

El-RamadyH,Abdalla N, Taha HS, Alshaal T,El-Henawy A, FaizySE-DA, ... Fári M. (2015). Se and nano-Se in plant nutrition. Environmental ChemistryLetters 14(1):123-147.

Hassanin KMA, El-Kawi SHA, Hashem KS (2013). The prospective protective effect of selenium nanoparticles against chromium-induced oxidative and cellular damage in rat thyroid. International Journal of Nanomedicine 8:1713-1720.

Huang B, ZhangJ, Hou J, Chen C (2003). Free radical scavenging efficiency of nano-Se in vitro. Free Radicals in Biology and Medicine 35(7):805 813.

Islam MZ, Mele MA, Baek JP, Kang H-M (2018). Iron, iodine and selenium effects on quality, shelf life and microbial activity of cherry tomatoes. Notulae Botanicae Horti Agrobotanici Cluj-Napoca 46(2):388-392.

JiangY,ZengZH,BuY, Ren CZ,LiJZ,HanJJ,...HuYG(2015).Effects of selenium fertilizer on grain yield, Se uptake and distribution in common buckwheat (Fagopyrum esculentum Moench). Plant, Soil and Environment 61(8):371-377.

Khoei NS, Lampis S, Zonaro E, Yrää̈ K, Bernardi P, Vallini G (2017). Insights into selenite reduction and biogenesis of elemental selenium nanoparticles by two environmental isolates of Burkholderia fungorum. New Biotechnology 34:1-11.

Piekarska A, Kołodziejski D, Pilipczuk T, Bodnar M, Konieczka P, Kusznierewicz B, ... Bartoszek A (2014). The influence of selenium addition during germination of Brassica seeds on health-promoting potential of sprouts. International Journal of Food Science and Nutrition 65(6):692-702.

Ramos SJ, Faquin V, Guilherme LRG, Castro EM, Ávila FW, Carvalho GS, Bastos CEA, Oliveira C (2010). Selenium bio fortification and antioxidant activity in lettuce plants fed with selenate and selenite. Plant, Soil and Environment 56(12):584588.

Reilly C (2006). Selenium in food and health. 2nd ed., Springer, US, New York.
Rychlik J, Olejnik A, Olkowicz M, Kowalska K, Juzwa W, Myszka K, ... Grajek W (2015). Antioxidant capacity of broccoli sprouts subjected to gastrointestinal digestion. Journal of Science of Food and Agriculture 95(9):1892-1902.

Sajedi N, Madani H, Naderi A (2011). Effect of microelements and selenium on superoxide dismutase enzyme, malondialdehyde activity and grain yield maize (Zea mays L.) under water deficit stress. Notulae Botanicae Horti Agrobotanici Cluj-Napoca39(2):153-159.

Sharma KD, Stähler K, Smith B, Melton L (2011). Antioxidant capacity, polyphenolics and pigments of broccoli-cheese powder blends. Journal of Food Science Technology 48(4):510-514.

Singleton VL, Orthofer R, Lamuela-Raventos RM (1999). Analysis of total phenols and other oxidation substrates and antioxidants by means of Folin-Ciocalteu reagent. Methods Enzymology 299:152-178.

Štolfa I, Velki M, Vuković R, Ečimović S, Katanić Z, Lončarić Z (2017). Effect of different forms of selenium on the plant-soil-earthworm system. Journal of Plant Nutrition and Soil Science 180(2):231-240.

Taran N, Batsmanova L, Kovalenko M, Okanenko A (2016). Impact of metal nanoform colloidal solution on the adaptive potential of plants. Nanoscale Research Letters 11(1):1-6.

TarasevičienėŽ, Danilčenko H, Jarienė E, Paulauskienė A, Marek Gajewski $M$ (2009). Changes in some chemical components during germination of broccoli seeds. Notulae Botanicae Horti Agrobotanici Cluj-Napoca 37(2):173-176.

Tian Q, Rosselot RA, Schwartz SJ (2005). Quantitative determination of intact glucosinolates in broccoli, broccoli sprouts, Brussels sprouts, and cauliflower by high-performance liquid chromatography-electrospray ionization-tandem mass spectrometry. Analytical Biochemistry 343(1):93-99.

Trolove SN, Tan Y, Morrison SC, FengL, Eason J (2018). Development of a method for producing selenium-enriched radish sprouts. LWT-Food Science and Technology 95:187-192.

Vicas SI, Teusdea A, Carbunar M, Socaci S, Socaciu C (2013). Glucosinolates profile and antioxidant capacity of Romanian brassica vegetables obtained by organic and conventional agricultural practices. Plant Foods for Human Nutrition 68(3):313-321.

ZhangJ, Taylor EW, Wan X, Peng D (2012). Impact of heat treatment on size, structure and bioactivity of elemental selenium nanoparticles. International Journal of Nanomedicine 7:815-825.

Zhang J, Wang X, Xu T (2008). Elemental selenium as a potential chemopreventive agent with reduced risk of selenium toxicity: comparison with methylselenocysteine in mice. Toxicology Science $101: 22-31$ 